the time of this observation from oh. $43 \mathrm{~m}$. to oh, $8 \mathrm{~m}$. p.m. was discussed, and it was resolved to accede to the proposal, notwithstanding the inconvenience which the change might entail in individual systems of observation.

The Proposal for Concerted Arctic Observations. - The International Polar Commission appointed at Hamburg, in October, 1879, presented a report of a meeting it had recently held at Berne, and announced that Count Wilczelk and Licut. Weyprecht had consented to postpone their expedition to Nova Zembla until 1882 in order to allow of more time for the organisation of the other expeditions destined to co-operate with them. The International Committee resolved to aid the scheme by all the means in their power.

The Publication of Data referring to Rain, $\mathcal{S}^{\circ} c_{0}$ - A proposal utade by Dr. Köppen for an improved method of publication of information relating to rain, snow, \&c., was ordered to be circulated among the different observatories, in order to obtain opinions as to its suitability.

Telegraphic Communication with the Atlantic Islands.-Capt. Hoffmeyer submitted a resolution as to the desirability of laying cables to the Faroes, Iceland, Greenland, and to the Azores. The Committee expressed their hope that it naight be found possible to lay these cables, which would be of very great importance for the weather service of Europe.

The Publicacion of Average Values for Meteorological Data.The Committee, at Capt. Hoffmeyer's suggestion, recommended that all meteorological organisations should publish regularly the mean values for the most important elements for the telegraphic and international stations.

The Catalogue of Meteorological Literature.-A proposal made by Dr. Hellmann of Berlin for the preparation of such a catalogue was considered. Dr. Hellmann stated that he had calculated the cost of preparation of the catalogue of printed books and memoirs at about $550 l$., and that of printing and publication ( $x, 000$ copies) at about $750 l$.

Several of the members of the Committee promised to aid in carrying out the scheme, if it were seriously undertaken, by the preparation of catalogues of the literature which exists in their own individual languages. The subject was finally referred to Mr. Scott and Dr. Hellmann, with power to act if they found sufficient encouragement.

As to the catalogue of unpublished records of observations, no definite resolution was adopted.

International Tables for the Reduction of Observations.-- It was stated that a publishing firm in Leipzig was prepared to print and publish such tables at its own risk if the "copy" were delivered to them. The subject was referred to Prof. Mascart and Prof. Wild for the preparation of a definite plan for the calculation of the tables.

The Committee will include in its Report, which will shortly appear, a notice of the progress made in each country in carrying out the resolutions of the Congress of Rome.

It only remains to say that the members of the Committce were most hospitably entertained by the Federal Council and by the Municipality of Berne.

\section{AGRICULTURAL CHEMISTRY 1}

SOME of my predecessors in this chair, whose duties as teachers of chemistry lead them to traverse a wide range of the subject every year, have appropriately and usefully presented to the Section a résums of the then recent progress in the manifold branches of the science which have now such far-reaching ramifications. Some, on the other hand, have confined attention to some department with which their own inquiries have more specially connected them.

But it seems to me that there is a special reason why I should bring the subject of 'Agricultural Chemistry before you on the present occasion. Not only is the application of chemistry to agriculture included in the title of this Section, but in 1837 the Committee of the Section requested the late Baron Liebig to prepare a report upon the then condition of Organic Chemistry, and it is now exactly forty years since Liebig presented to the British Association the first part of his report, which was entitled "Organic Chemistry in its Applications to Agriculture and Physiology "; and the second part was presented two years later, in I 842 , under the title of "Animal Chemistry, or Organic Chemistry

${ }^{I}$ Opening Address in Section B (Chemical Science), at the Swansea meeting of the British Association, by J. H. Gilbert, Ph.D., F.R.S., in its Application to Physiology and Pathology." Yet, so far as I am aware, no President of the Section has, from that time to the present, taken as the subject of his address the Application of Chemistry to Agriculture.

Appropriate as, for these reasons, it would seem that I, who have devoted a very large portion of the interval since the publication of Liebig's works, above referred to, to agricultural inquiries, should occupy the short time that can be devoted to such a purpose in attempting to note progress on that important subject, it will be readily understood that it would be quite impossible to condense into the limits of an hour's discourse anything approaching to an adequate account, either of the progress made during the last forty years, or of the existing condition of agricultural chemistry.

For what is agricultural chemistry? It is the chemistry of the atmosphere, the chemistry of the soil, the chemistry of vegetation, and the chemistry of animal life and growth. And but a very imperfect indication of the amount of labour which has been devoted of recent years to the investigation of these various branches of what might at first sight seem a limited subject will suffice to convince you how hopeless a task it would be to seek to do more than direct attention to a few points of special interest.

From what we now know of the composition and of the sources of the constituents of plants, it is obvious that a knowledge of the composition of the atmosphere and of water was essential to any true conception of the main features of the vegetative process; and it is of interest to observe that it was almost simultaneously with the establishment, towards the end of the last century, of definite knowledge as to the composition of the air and of water, that their mutual relations with vegetation were first pointed out. To the collective labours of Black, Scheele, Priestly, Lavoisier, Cavendish, and Watt, we owe the knowledge that common air consists chiefly of nitrogen and oxygen, with a little carbonic acid; that carbonic acid is composed of carbon and oxygen; and that water is composed of hydrogen and oxygen; whilst Priestly and Ingenhousz, Sennebier and Woodhouse, investigated the mutual relations of these bodies and vegetable growth. Priestly observed that plants possessed the faculty of purifying air vitiated by combustion or by the respiration of animals ; and, he having discovered oxygen, it was found that the gaseous bubbles which Bonnet had shown to be emitted from the surface of leaves plunged in water consisted principally of that gas. Ingenhousz demonstrated that the action of light was essential to the development of these phenomena; and Sennebier proved that the oxygen emitted resulted from the decomposition of the carbonic acid taken up.

De Saussure concluded that air and water contributed a much larger proportion of the dry substance of plants than did the soils in which they grew. In his view a fertile soil was one which yielded liberally to the plant nitrogenous compounds, and the incom. bustible or mineral constituents; whilst the carbon, hydrogen, and oxygen, of which the greater proportion of the dry substance of the plant was made up, were at least mainly derived from the air and water.

Perhaps I ought not to omit to mention here that, each year for ten successive years, from 1802 to 18 I 2, Sir Humphry Davy'delivered a course of lectures on the "Elements of Agricultural Chemistry," which were first published in 1813 , were finally reviser by the author for the fourth edition in 1827 , but have gone through several editions since. In those lectures Sir Humphry Davy passed in review and correlated the then existing knowledge, both practical and scientific, bearing upon agriculture. He treated of the influences of heat and light; of the organisa. tion of plants ; of the difference, and the change, in the chemical composition of their different parts ; of the sources, composition, and treatment of soils; of the composition of the atmosphere, and its influence on vegetation; of the composition and the action of manures; of fermentation and putrefaction; and finally of the principles involved in various recognised agricultural practices.

With the exception of these discourses of Sir Humphry Davy, the subject seems to have received comparatively little attention, nor was any important addition made to our knowledge in regari to it during the period of about thirty years from the date of the appearance of De Saussure's work in 1804 to that of the com. mencement of Boussingault's investigations.

In 1837 Boussingault published papers on the amount of gluten in different kinds of wheat, on the influence of the clearing of forests on the diminution of the flow of rivers, and on the 
meteorological influences affecting the culture of the vine. In 1838 he published the results of an elaborate research on the principles underlying the value of a rotation of crops. $\mathrm{He}$ determined by analysis the composition, both organic and inorganic, of the manures applied to the land, and of the crops harvested. In his treatment of the subject he evinced a clear perception of the most important problems involved in such an inquiry; some of which, with the united labours of himself and many other workers, have scarcely yet received an undisputed solution.

Thus, in the same year $(1838)$, he published the results of an investigation on the question whether plants assimilate the free or uncombined nitrogen of the atmosphere; and although the analytical methods of the day were inadequate to the decisive settlement of the point, his conclusions were in the main those which much subsequent work of his own, and much of others also, has served to confirm.

The foregoing brief historical sketch is sufficient to indicate, though but in broad outline, the range of existing knowledge on the subject of agricultural chemistry prior to the appearance of Liebig's memorable work in 1840 . It will be seen that some very important and indeed fundamental facts had already been established in regard to vegetation, and that Boussingault had not only extended inquiry on that subject, but he had brought his own and previous results to bear upon the elucidation of long recognised agricultural practices. There can be no doubt that the data supplied by his researches contributed important elements to the basis of established facts upon which Liebig founded his brilliant generalisations. Accordingly, in 184I, Dumas and Boussingault published jointly an essay which afterwards appeared in English under the title of "The Chemical and Physiological Balance of Organic Nature;" and in 1843 Boussingault published a larger work, which embodied the results of many of his own previous original investigations.

The appearance of Liebig's two works, which were contributions made in answer to a request submitted to him by the committee of this Section of the British Association, constitute a very marked epoch in the history of the progress of agricultural chemistry. In the treatment of his subiect he not only called to his aid the previously existing knowledge directly bearing upon it, but he also turned to good account the more recent triumphs of organic chemistry, many of which had been won in his own laboratory. Further, a marked feature of his expositions was the adoption of what may be called the statistical method-I use the word statistical rather than quantitative, as the latter expression has its own technical meaning among chemists, which is not precisely what I wish to convey.

The discussion of the processes of fermentation, decay, and putrefaction, and that of poisons, contagions, and miasms, constituted a remarkable and important part of Liebig's first report. It was the portion relating to poisons, contagions, and miasms, that he presented to this Section as an instalment, at the meeting of the Association held at Glasgow in 1840 . It was in the chapters relating to the several subjects here enumerated that he developed so prominently his views on the influence of contact in inducing chemical changes. He cited many known transformations, other than those coming under either of the heads in question, in illustration of his subject; and he discussed with great clearness the different conditions occurring, and the different results obtained, in various processes-such as the different modes of fermenting beer, the fermentation of wine from different kinds of grapes, the production of acetic acid, \&c. As is well known, he claimed a purely chemical explanation for the phenomena involved in fermentation. He further maintained that the action of contagions was precisely similar. In his latest writings on the subject (in 1870 ) he admits some change of view; but it is by no means easy to decide exactly how much or how little of modification he would wish to imply.

Liebig's second report, presented at the meeting of this Association in 1842 , and published under the title of "Animal Chemistry, or Organic Chemistry in its Applications to Physiology and Pathology," perhaps excited even more attention than his first; and, probably from the manner as much as from the matter, aroused a great deal of controversy, especially among physiologists and physicians. Liebig was severe upon what he considered to be a too exclusive attention to morphological characters in physiological research, and at any rate too little attention to chemical phenomena, and, so far as these were investigated, an inadequate treatment of the subject according to strictly quantitative methods.
Omitting the fat which the carnivora might receive in the animals they consumed, he stated the characteristic difference between the food of carnivora and herbivora to be, that the former obtained the main proportion of their respiratory material from the waste of tissue; whilst the latter obtained a large amount from starch, sugar, \&c. These different conditions of life accounted for the comparative leanness of carnivora and fatness of herbivora.

He maintained that the vegetable food consumed by herbivora did not contain anything like the amount of fat which they stored up in their bodies; and he showed how nearly the composition of fat was obtained by the simple elimination of so much oxygen, or of oxygen and a little carbonic acid, from the various carbohydrates. Much less oxygen would be required to be eliminated from a quantity of fibrine, \&c., containing a given amount of carbon, than from a quantity of carbohydrates containing an equal amount of carbon. The formation of fatty matter in plants was of the same kind; it was the result of a secondary action, starch being first formed from carbonic acid and water.

He concluded from the facts adduced that the food of man might be divided into the nitrogenised and the non-nitrogenised elements. The former were capable of conversion into blood, the latter incapable of such transformation. The former might be called the plastic elements of nutrition, the latter elements -of respiration. From the plastic elements, the membranes and cellular tissue, the nerves and brain, cartilage, and the organic part of bones, could be formed; but the plastic substance must be received ready-made. Whilst gelatine or chondrine was derived from fibrine or albumen, fibrine or albumen could not be [reproduced from gelatine or chondrine. The gelatinous t'ssues suffer progressive alteration under the influence of oxygen, and the materials for their re-formation must be restored from the blood. It might however be a question whether gelatine taken in food might not again be converted into cellular tissue, membrane, and cartilage, in the body.

Apparently infuenced by the physiological considerations which have been adduced, and notwithstanding in some passages he seemed to recognise a connection between the total quantity of oxygen inspired and consumed and the quantity of mechanical force developed, Liebig nevertheless very prominently insisted that the amount of muscular tissue transformed-the amount of nitrogenous substance oxidated-was the measure of the force generated. He accordingly distinctly draws the conclusion that the requirement for the azotised constituents of food will be increased in proportion to the increase in the amount of force expended.

It will be obvious that the question whether in the feeding of animals for the exercise of mechanical force, that is, for their labour, the demands of the system will be proportionally the greater for an increased supply of the nitrogenous or of the nonnitrogenous constituents of food, is one of considerable interest. and practical importance. To this point I shall have to refer further on.

So far, I have endeavoured to convey some idea of the state of knowledge on the subject of the chemistry of agriculture prior to the appearance of Liebig's first two works bearing upon it, and also briefly to summarise the views he then enunciated in regard to some points of chief importance. Let us next try to ascertain something of the influence of his teaching.

Confining attention to agricultural research, it may be observed that about the year 1843 , that is very soon after the appearance of the works in question, there was established the ChemicoAgricultural Society of Scotland, which was, I believe, broken up, after it had existed about five years, because its able chemist, the late Prof. Johnston, was unable to find a remedy for the potato disease. Shortly after this, the Highland and Agricultural Society of Scotland appointed a consulting (chemist; somewhat later the Royal Agricultural Society of England did the same and later still followed the Chemico-Agricultural Society of Ulster. Lastly, the very numerous "Agricultural Experimental Stations" which have been established, not only in Germany, but in most. Continental States, owe their origin directly to the writings, the teachings, and the influence of Liebig. The move ment seems to have originated in Saxony, where Stöckhardt had already stimulated interest in the subject by his lectures and his writings. After some correspondence, in $1850-5 \mathrm{I}$, between the late Dr. Crucius and others on the one side, and the Government on the other, the first so-called "Agricultural Experimental Sta- 
tion" was established at Möchern, near Leipzig, in 1851-52. In I 877 the twenty-fifth anniversary of the foundation of that institution was celebrated at Leipzig, when an account (which has since been published) was given of the number of stations then existing, of the number of chemists engaged, and of the subjects which had been investigated. From that statistical statement we learn that in 1877 the number of stations was 122 .

Besides these stations on the Continent of Europe, the United States are credited with one, and Scotland also with one.

Each of these stations is under the direction of a chemist, frequently with one or more assistants. One special duty of most of them is what is called manure- or seed- or feeding-stuffcontrol; that is, to examine or analyse, and report upon such substances in the market, and it seems to have been found to the interest of dealers in these commodities to submit their proceedings to a certain degree of supervision by the chemist of the station of their district.

But agricultural research has always been a characteristic feature of these institutions. It is stated that the investigation of soils has been the prominent object at 16 of them, experiments with manures at 24 , vegetable physiology at 28 , animal physiology and feeding experiments at 20 , vine culture and wine making at $\mathrm{I} 3$, forest culture at 9 , and milk production at Ir, Others, according to their locality, have devoted special attention to fruit culture, olive culture, the cultivation of moor, bog, and peat land, the production of silk, the manufacture of spirit, and other products.

Nor does this enumerations of the institutions established as the direct result of Liebig's influence, and of the subjects investigated under their auspices, complete the list either of the workers engaged, or of the work accomplished in agricultural research. To say nothing of the labours of Boussingault, which commenced some years prior to the appearance of Liebig's first work, and which are fortunately still at the service of agriculture, important contributions have been made by the late Professors Johnston and Anderson in Scotland, and in this country both by $\mathrm{Mr}$. Way and Dr. Voelcker, each alike in his private capacity, and in fulfilment of his duties as Chemist to the Royal Agricultural Society of England. Nor would it be fair to Mr. Lawes (who commenced experimenting first with plants in pots, and afterwards in the field, soon after entering into possession of his property in 1834, and with whom I have myself been associated since 1843), were I to omit in this place any mention of the investigations which have been so many years in progress at Rothamsted.

So much for the machinery; but what of the results achieved by all this activity in the application of chemistry to agriculture?

The more I have looked at the subject with the hope of treating it comprehensively, the more I have been impelled to substitute a very limited plan for the much more extended scheme which I had at first hoped to be able to fill up. I propose then to con. fine attention to a few special points, which have either some connection with one another, or to which recent results or discussions lend some special interest.

First as to the sources and the assimilation of the carbon, the hydrogen, and the oxygen of vegetation. From the point of view of the agricultural chemist, the hydrogen and the oxygen may be left out of view. For, if the cultivator provide to the plant the conditions for the accumulation of sufficient nitrogen and carbon, he may leave it to take care of itself in the matter of hydrogen and oxygen. That the hydrogen of the carbohydrates is exclusively obtained from water, is, to say the least, probable; and whether part of their oxygen is derived from carbonic acid, and part from water, or the whole from either of these, will not affect his agricultural practice.

With regard to the carbon, the whole tendency of subsequent observations is to confirm the opinion put forward by Dr. Saussure about the commencement of the century, and so forcibly insisted upon by Liebig forty years later-that the greater part, if not the whole of it, is derived from the carbonic acid of the atmosphere. Indeed, direct experiments are not wanting-those of Moll, for example-from which it has been concluded that plants do not even utilise the carbonic acid which they may take ap from the soil by their roots. However this may be, we may safely conclude that practically the whole of the carbon which it is the object of the cultivator to force the plants he grows to take up is derived from the atmosphere, in which it exists in uch extremely small proportion, but nevertheless large actual, and constantly renewed amount.

Judging from the more recent researches on the point, it would seem probable that the estimate of one part of carbon, as carbonic acid, in 10,000 of air, is more probably too high than too low as an estimate of the average quantity in the atmosphere of our globe. And, although this corresponds to several times more in the column of air resting over an acre of land than the vegetation of that area can annually take up, it represents an extremely small amount at any one time in contact with the growing plants, and could only suffice on the supposition of a very rapid renewal accomplished as the result, on the one hand, of a constant return of carbonic acid to the atmosphere by com bustion and the respiration of a.rimals, and, on the other, of a constant interchange and equalisation among the constituents of the atmosphere.

It will convey a more definite idea of what is accomplished by vegetation in the assimilation of carbon from the atmosphere if $I$ give, in round numbers, the results of some direct experiments made at Rothamsted, instead of making general statements merely.

In a field which has now grown wheat for thirty seven years in succession there are some plots to which not an ounce of carbon has been returned during the whole of that period. Yet, with purely mineral manure, an average of about $r, 000$ pound's of carbon is annually removed from the land; and where a given amount of nitrogenous manure is employed with the mineral manure, an average of about 1,500 pounds per acre per annum more is obtained; in all an average of about 2,500 pounds of carbon annually assimilated over an acre of land without any return of carbonaceous manure to it.

In a field in which barley has been grown for twenty-nine years in succession, quite accordant results have been obtained. There smaller amounts of nitrogenous manure have been employed with the mineral manure than in the experiments with wheat above cited ; but the increase in the assimilation of carbon for a given amount of nitrogen supplied in the manure is greatcr in the case of the barley than of the wheat.

With sugar-beet again, larger amounts of carbon have been annually accumulated without the supply of any to the soil, burt under the influence of a liberal provision of both nitrogenous and mineral manure, than by either wheat or barley.

Lastly, with grass, still larger amounts of carbon have been annually accumulated, without any supply of it by manure.

Many experiments have been made in Germany and elsewhere, to determine the amount of the different constituents taken up at different periods in the growth of various plants. But we may refer to some made at Rothamsted long ago to illustrate the rapidity with which the carbon of our crops may be withdrawn from the atmosphere.

In 1847 we carefully took samples from a growing wheat crop at different stages of its progress, commencing on June 21 , and in these samples the dry matter, the mineral matter, the nitrogen, \&c., were determined. On each occasion the produce of two separate eighths or sixteenths of an acre was cut and weighed, so that the data were provided to calculate the amounts of the several constituents which had been accumulated per acre at each period. The result was that, whilst during little more than tive weeks from June 21 there was comparatively little increase in the amount of nitrogen accumulated over a given area, more than half the total carbon of the crop was accumulated during that period.

I should say that determinations of carbon, made in samples of soil taken from the wheat-field at different periods during recent years, indicate some decline in the percentage of carbon in the soils, but not such as to lead to the supposition that the soils have contributed to the carbon of the crops. Besides the amount of carbon annually removed, there will of course be a further accumulation in the stubble and roots of the crops; and the reduction in the total carbon of the soil, if such have really taken place, would show that the annual oxidation within the soil is greater than the annual gain by the residue of the crops.

Large as is the annual accumulation of carbon from the atmosphere over a given area in the cases cited, it is obvious that the quantity must vary exceedingly with variation of climatal conditions. It is, in fact, several times as great in the case of tropical vegetation-that of the sugar-cane, for example. And not only is the greater part of the assimilation accomplished within a comparatively small portion of the year (varying of course according to the region), but the action is limited to the hours of daylight, whilst during darkness there is rather loss than gain.

But it is remarkable that whilst the accumulation of carbon, the chief gain of solid material, takes place under the influence 
of light, cell-division, cell-multiplication, increase in the structure of the plant, in other words, what, as distinguished from assimilation, vegetable physiologists designate as growth, takes place, at any rate chiefly, during the night; and is accompanied, not with the taling up of carbonic acid and the yielding up of oxygen, but with the taking up of oxygen and the giving up of carbonic acid. This evolution of carbonic acid during darkness must obviously be extremely small, compared with the converse action during daylight, coincidentally with which practically the whole of the accumulation of solid substance is accomplished. But as the product of the night action is the same as in the respiration of animals, this is distinguished by vegetable physiologists as the respiration of plants.

I suppose I shall be considered a heretic if I venture to suggest that it seems in a sense inappropriate to apply the term growth to that which is associated with actual loss of material, and that the term respiration should be applied to so secondary an action as that as the result of which carbonic acid is given off from the plant. It may, I think, be a question whether there is any advantage in thus attempting to establish a parallelism between animal and vegetable processes; rather would it seem advantageous to keep prominently in view their contrasted, or at any rate complementary characteristics, especially in the matter of the taking up of carbonic acid and the giving up of oxygen on the one hand, and the taking in of oxygen and the giving up of carbonic acid on the other.

But it is obvious that in latitudes where there is comparatively continuous daylight during the periods of vegetation, the two actions-designated respectively assimilation and growth-must go on much more simultaneously than where there is a more marked alternation of daylight and darkness. In parts of Norway and Sweden, for example, where during the summer there is almost continuous daylight, crops of barley are grown with only from six to eight weeks intervening from seed-time to harvest. And Prof. Schibeler, of Christiania, after making observations on the subject for nearly thirty years, has recently described the characteristics of the vegetation developed under the influence of short summers with almost continuous light. $\mathrm{He}$ states that, after acclimatisation, many garden flowers increase in size and depth of colour; that there is a prevailing tinge of red in the plants in the fjelds; that the aroma of fruits is increased, and their colour well developed, but that they are deficient in sweetness; and that the development of essential oils in certain plants is greater than in the same plants grown in other latitudes. Indeed he considers it to be an established fact that light bears the same relation to aroma as heat does to sweetness.

In connection with this question of the characters of growth under the influence of continuous light, compared with those developed with alternate, light and darkness, the recent experiments of Dr. Siemens on the influence of electric light on vegetation are of considerable interest.

In one series of experiments he kept one set of plants entirely in the dark, a second he exposed to electric light only, a third to daylight only, and a fourth to daylight and afterwards to electric light from 5 to II p.m. Those kept in the dark acquired a pale yellow colour, and died; those exposed to electric light only maintained a light green colour, and survived; those exposed to daylight were of a darker green colour, and were more vigorous; and, lastly, those submitted to alternate daylight and electric light, and but a few hours of darkness, showed decidedly greater vigour, and, as he says, the green of the leaf was of a dark rich hue. He concluded that daylight was twice as effective as electric light ; but that, nevertheless, "electric light was clearly sufficiently powerful to form chlorophyll and its derivatives in the plants."

In a second series of experiments one group of plants was exposed to daylight alone; a second to electric light during eleven hours of the night, and was kept in the dark during the day; and a third to eleven hours day, and eleven hours electric light. The plants in daylight showed the usual healthy appearance; those in alternate electric light and darkness were for the most part of a lighter colour; and those in alternate daylight and electric light far surpassed the others in darkness of green and vigorous appearance generally.

I have carefully considered these general descriptions with a view to their bearing on the question whether the characters developed under the influence of electric light, and especially those under the influence of almost continuous light, are more prominently those of assimilation or of growth; but $I$ have not been able to come to a decisive opinion on the point. From some conversation I had with Dr. Siemens on the subject, I gather that the characteristics were more those of dark colour and vigour than of tendency to great extension in size. The dark green colour we may suppose to indicate a liberal produc. tion of chlorophyll ; but if the depth of colour was more than normal it might be concluded that the chlorophyll had not performed its due amount of assimilation work. In regard to this point attention may be called to the fact that Dr. Siemens refers to the abundance of the blue or actinic rays in the electric arc, conditions which would not be supposed specially to favour assimilation. On the other hand, the vigour, rather than characteristic extension in size, would seem to indicate a limitation of what is technically called growth, under the influence of the almost continuous light.

Among the numerous field experiments made at Rothamsted, we have many examples of great variation in depth of green colour of the vegetation growing on plots side by side under known differences as to manuring; and we have abundant evidence of difference of composition, and of rate of carbonassimilation, coincidently with these different shades of colour. One or two instances will strikingly jllustrate the point under consideration.

The point of special interest is, however, that all but identically the same amount of nitrogen has been taken up by the herbage growing with the deficiency of potass as by that with the continued supply of it. The colour of the vegetation with the deficiency of potass has been very much darker green than that with the full supply of it.

An equal amount of nitrogen was taken up in both cases, chlorophyll was abundantly produced, but the full amount of carbon was not assimilated. In other words, the nitrogen was there, the chlorophyll was there, there was the same sunlight for both plots; but the assimilation-work was not done where there was not a due supply of potass.

It may be stated generally that, in comparable cases, depth of green colour, if not beyond a certain limit, may be taken to indicate corresponding activity of carbon assimilation; but the two instances cited are sufficient to show that we may, so far as the nitrogen, the chlorophyll, and the light are concerned, have the necessary conditions for full assimilation, but not corresponding actual assimilation.

It cannot, I think, fail to be recognised that in these considerations we have opened up to view a very wide field of research, and some of the points involved we may hope will receive elucidation from the further prosecution of Dr. Siemens's ex. periments. He will himself, I am sure, be the first to admit that what he has already accomplished has done more in raising than in settling important questions. I understand that he proposes to submit plants to the action of the separated rays of his artificial light, and the results obtained cannot fail to be of much interest. But it is obvious that the investigation should now pass from its present initiative character to that of a strictly quantitative inquiry. We ought to know not only that, under given conditions as to light, plants acquire a deeper green colour, and attain maturity much earlier than under others, but how much matter is assimilated in each case, and something also of the comparative chemical characters of the products. As between the action of one description of light and another, and as between the greater or less continuity of exposure, we ought to be able to form a judgment whether the proper balance between assimilation on the one hand, and growth and proper maturation on the other, has Leen attained; whether the plants have taken up nitrogen and mineral matter and produced chlorophyll in a greater degree than the quantity and the quality of the light have been able to turn to account; or whether the conditions as to light have been such that the processes of transformation and growth from the reserve material provided by assimilation have not been normal or have not kept pace with the production of that material.

But one word more in reference to Dr. Siemens' results and proposed extension of his inquiries. Even supposing that by submitting growing crops to continuous light by the aid of the electric light during the night, they could be brought to maturity within a period shorter than at present approximately in proportion to the increased number of hours of exposure, the estimates of the cost of illuminating the vegetation of an acre of land certainly do not seem to hold put any hope that agriculture is likely to derive benefit from such an application of science to its needs. If, however, the characters of growth and of maturation should 
prove to be suitable for the requirements of horticultural products of luxury and high value, it may possibly be otherwise with such productions.

The above considerations obviously suggest the question : What is the office of chlorophyll in the processes of vegetation? Is it, as has generally been assumed, confined to effecting, in some way not yet clearly understood, carbon assimilation, and, this done, its function ended; or is it, as Pringsheim has recently suggested, chiefly of avail in protecting the subjacent cells and their contents from those rays of light which would be adverse to the secondary processes which have been distinguished as growth?

Appropriate as it would seem that I should attempt to lay before you a résumé of results bearing upon the points herein involved, so numerous and so varied have been the investigations which have been undertaken on the several branches of the question in recent years, that adequately to discuss them would occupy the whole time and space at my disposal. I must therefore be content thus to direct attention to the subject, and pass on to other points.

(To be continued.)

\section{THE BRITISH ASSOCIATION REPORTS}

Report on the Tertiary Flora of the Basalts of the North of Ireland, by Mr. W. H. Baily.-Described the plants of Miocene deposits, consisting of variegated marls, resting on a leaf-bed near Glenarm. Amongst the plants were Sequoia couttsia, $S$. lyelli, Fagus deucalium, Nyssa ornithobroma, Aralis brozenia, Fraxinus guillelma. These and others have been drawn and described.

Report on the Viviparous Nature of the Ichthyosauri, by Prof. H. C. Seeley.-Dr. Channen Pierce had formerly described a specimen of Ichthyosaurus in the Museum at Bristol which he considered contains a foetus in the act of coming into the world, which view is supported by Prof. Seeley, who showed, reasoning by the analogy of the stomach of a crocodile, it was impossible that this animal could have swallowed a smaller ichthyosaurus, and its remains been retained in the stomach in a perfect fform, and alludes to the spiral structure of the coprolite, pointing to a small intestine, and thought it is impossible that the animal could have passed through them in the process of digestion; and alluded to the fact that all German specimens show the head of the smaller projecting towards the tail of the larger, though the reverse is the case in a specimen at Madrid. But in Tübingen the most perfect specimens occur, in which the smaller animals are found lying completely preserved between the ribs of the parent animal; though, he suggests, in all cases viviparous characters may not have obtained in all forms of ichthyosauri.

The Sixth Report of the Underground Water Committee was read by Mr. De Rance, who pointediout that the watershed separating the basins of the Thames and. Eastern Counties from those of the Humber and the Severn also divides the area of heaviest rainfall on the Palæozoic rocks, which are nearly all impermeable, from those of Secondary age, receiving a rainfall of about 30 inches. West of this line, with the exception of the Trias, no Secondary rocks occur. In Lancashire, Cheshire, and the Midlands the Triassic Sandstones absorb about one-third of the rainfall, giving a daily average of 400,000 gallons to each square mile of country : wells in these rocks are capable of drawing on several square miles, and in suitable situations of yielding from 2 to 3 million gallons per day. The discovery of the Manchester coalfield beds at Winwick, near Warrington, under the New Red Sand. stone, at a depth of only 340 feet, was described. He referred to the position of the New Red boring at Bootle, for the Liverpool Corporation water supply, as very badly chosen, being close to one of the existing wells. He then showed the gradual attenuation in thickness of the Bunter Sandstones, in a southerly direction, against the old Palacozoic axis, ranging from the Belgian coalfield to the Mendips.

Report on the Present State of our Inowledge of the Crustacea, by C. Spence Bate, F.R.S. - This is Part v. of the Report, and deals with the subjects of fecundation, respiration, and the green gland.
SECTION A.-MAThematical And Physical

Improved Apparatus for the Objective Estimation of Astigmatism, by Tempest Anderson, M.D., B.Sc.-Astigmatism has been defined as that condition of the eye in which refraction is unequal in the different meridians. In order to obtain suitable spectacles for correcting this defect, it is necessary to know accurately the focal adjustment of the meridians of maximum and minimum curvature, whence the focal lengths of glasses, generally either cylindrical or cylindrical on one side and spherical on the other, are readily calculated. Many plans have been adopted for determining this; some subjective, depending on observations made by the eye itself, and generally using a point of light or a series of radiating lines as an object. From their appearances when viewed at different distances, and with lenses of different powers, the focal adjustment of the different meridians is at last obtained.

The advantage of this group of methods is their theoretical delicacy, as they work by judging of the perfection of certain images refracted on the retina in a manner not very dissimilar to that in which they are usually formed; the practical disadvantage, that accurate observations are required from one who has never been accustomed to make them. Hence objective methods have been introduced. Their advantages are, substituting trained for untrained observation. Their disadvantages-

r. The vessels of the retina and the optic nerves, which are mostly employed as objects, are seldom in exactly the position desirable for estimating the refraction in different meridians, and are often at a different distance from the optical system of the eye from that at which the sensitive layer of the retina lies.

2. They mostly require the optical defects, if any, and the accommodation of the observing eye to be taken into account and allowed for, thus introducing risk of error.

In the author's two instruments, an image of a suitable object thrown on the retina of the observed eye, is used as an object by the observer, with the following advantages :-

I. The patient's sensations may be entirely disregarded, or only used as confirmatory.

2. The image used is necessarily at the retina, and not before or behind it.

3. The accommodation or any defects in the refraction of the observer's eye does not enter into the result, as the only function of this eye is to observe the formation of the image on the retina.

In the first plan a lamp $l$ is provided with a condensing lens $c$, and a series of radiating wires $w$ (supposed to be seen edgeways in the figure), thus giving a bright field with black lines on it.

The whole slides on a graduated bar $C$, at the other end of which is a convex lens $y(4$ and Io dioptrics are the most convenient powers, i.e. 10 and 4 inch focus). Close to the lens, and at an angle of $45^{\circ}$ to its axis, is a plane mirror $(\mathrm{m})$, which reflects the rays at right angles to their former path. The instrument is to be held so that this pencil of rays enters the observed eyc, and when the wire screen is at the proper distance, an image of it is formed on the retina. The mirror has the centre left unsilvered, as in an ordinary ophthalmoscope, and has a disk of correcting lenses behind it, to render the retina, and the image on it, visible by the direct method. The ob. served eye should have its accommodation relaxed by atropine

The bar is so graduated that when an image of the whole or part of the screen is sharp on the retina, the figure opposite the screen expresses the refractive error of the meridian by which the image is produced. Hence if the image of the whole screen is seen to be equally sharp, the eye is known to be not astigmatic, and the gradustion given the number of dioptrics by which it is myopic or hypermetropic. If the lines be not all sharp at once, then the most distant point at which a distinct image of any of the wires is formed on the retina gives the refractive crror of the meridian of minimum refraction (expressed in dioptrics), and the point at which the line at right angles to this is best defincd, gives that of the meridian of maximum refraction. The least of these gives the spherical element of the correcting lens required for distant objects, and the difference between the two gives that of the cylindrical part. The meridian of maximum refraction is that in which the line is visible when the wires are at the greatest distance.

In the second plan the lamp, $l$, condensing lens, $c$, and wire screen, $w$, are similar, and only differ in size, the front lens, $y$, and mirror, $m$, arc also similar, but the lamp and wires are permanently fixed by a tube, so that the wires are accurately in 